a bark beetle which kills its host tree following the attraction of massive numbers of beetles to particular volatile substances in frass and resin produced by the activity of perhaps no more than one initial beetle colonist.

The behavioural relationships of an insect to its host plant were emphasized in Professor J. S. Kennedy's and $\mathrm{Mr}$ I. H. M. Fosbrooke's (Imperial College, London) discussion on the plant in the life of an aphid. They suggested that the migratory aphid's flight behaviour continues to be influenced importantly by light reflected from plants irrespective of the height at which the insect is flying.

In discussing the plant in the population dynamics of insects, Dr H. F. van Emden (University of Reading) and Professor M. J. Way (Imperial College, London) pointed out that even "chemosensority susceptible" host plants often cause surprisingly large direct mortalities to populations of insects established on them. They also emphasized the role of the plant in providing the framework within which subtle density dependent effects of intraspecific competition operate.

The role of the host plant in the population dynamics of phytophagous insects is still very inadequately understood-and vice versa-as was shown by Dr P. Harris (Canada Department of Agriculture, Belleville), who used examples of successful biological control of weeds to show how introduced phytophagous insects have severely limited the distribution and abundance of a few introduced plant weeds. In general, however, the insect's effect on population dynamics of indigenous plant populations still seems to be largely a matter for speculation except in circumstances where the plant has become dependent for pollination on certain insects.

\section{PACIFIC SCIENCE}

\section{Island Conservation}

from a Correspondent

THE occasion of the twelfth Pacific Science Congress, held at the Australian National University from August 18 to 27 , was taken to celebrate the fiftieth anniversary of the Pacific Science Association which held its first meeting at Honolulu in 1920, under the presidency of its founder, Professor H. E. Gregory.

The congress was addressed by its president, Sir Macfarlane Burnet, after which the Gregory Medal was presented to Dr F. Raymond Fosberg (Smithsonian Institution), the Shinkishi Hatai Medal to Dr Carl L. Hubbs (Scripps Institution for Oceanography) and honorary life memberships were conferred on $\mathrm{Dr}$ Sarwono Prawirohardjo (Indonesia) and Sir Maurice Yonge (Great Britain).
Much of the programme of the congress had relevance to the International Biological Programme with its emphasis on conservation. The resolutions submitted by the council at the final meeting reflected the general concern about the environment which, even in remote Pacific islands, is being increasingly degraded by the effects of pesticides, of mining, of the cutting down of primaeval forests and, by no means least, the effect of tourism with its impact on the dignity of native peoples.

Such problems had been the particular concern of a regional symposium on the conservation of reefs and lagoons held before the congress, at Noumea, New Caledonia, under the auspices of the South Pacific Commission in collaboration with the International Union for the Conservation of Nature and Natural Resources (IUCN). A resolution coming from this symposium included reference to the urgent need for appropriate environmental and eologi- cal surveys being conducted before any "developmental" project. It also urged intergovernmental action on the imaginative "islands for science" proposal whereby a representative number of islands, largely uninhabited, could be set aside as permanent reserves unaffected by environmental changes induced by man.

It was also suggested that periodic surveys might be carried out on coral reef areas to record long-term fluctuations in the comparison of reef ecosystems. The importance of such knowledge is emphasized by the present widespread population explosion of the coral destroying starfish, Acanthaster planci. In this connexion, also, the Pacific Science Council established a new Com. mittee on the Scientific Study of Coral Reefs for the better coordination of work on reefs which, for a variety of uncertain reasons, are now widely endangered.

\title{
New Normal Geomagnetic Event
}

Determination of the detailed geomagnetic polarity-time scale from continental igneus rocks of the past four million years or so has proved a comparatively simple task, partly because the polarities of young fresh rocks unaffected by appreciable continental drift are determined easily and unambiguously, partly because radiometric dating of such rocks is less likely to be affected by such factors as mineral alteration, and partly because within this period the absolute errors of the potassium-argon dating process are small enough to enable polarity intervals of as short as a few tens of thousands of years to be resolved. For older rocks these advantages are lost; and so it seems unlikely that the detailed pattern of magnetic reversals will ever be delineated for tens or hundreds of millions of years, lest it be on the basis of ocean magnetic anomalies. The essential problem is that even if continental rocks ideal for radiometric dating and magnetic measurement are found, the inherent dating errors will always be larger than all but the longest geomagnetic polarity intervals.

But as Creer et al. point out in next Monday's Nature Physical Science, there is one geological period within which comparatively short magnetic intervals may be, if not resolved, at least located with a fair degree of precision. This is the period of about 60 million years within the upper Carboniferous and Permian during which the geomagnetic field polarity was apparently almost always reversed. Until recently no normal intervals at all were known within this Kiaman reversed period (about 235 to 290 million years).
McElhinny (Spec. Publs Geol. Soc. Austral., 2, 61 ; 1969), however, has reported a normal event at about 280 million years, which he named the Oak Creek event, and which Burek (Bull. Amer. Assoc. Petrol. Geol., 54, 1120 ; 1970) later renamed the Graham event. Less well documented is a second normal event present in Italian midPermian sediments as reported by Guicherit (Geologica Ultraiectina, 14, $1 ; 1964)$. But the point is that normal events within the Kiaman reversed interval seem to be so rare that a few which may remain to be discovered are likely to be easily distinguished from each other and from those already found.

And so it has proved in at least one case, for Creer and his colleagues have discovered a new normal event well separated in time from the Graham event. The rocks in question are basalts, andesites and rhyolites of the Porphyritic Series exposed in Mendoza Province, Argentina. All samples were magnetically cleaned; and so there can be no doubt that normal polarities exist within this series. Moreover, the normal palaeomagnetic directions are consistent with the Permian field of South America as determined from the more common reversed rocks within the Kiaman interval. The stratigraphic age of the samples lies between about 270 and 210 million years; but, more importantly, the potassium-argon ages of two of the normal samples are $262 \pm 6$ and $264 \pm 6$ million years, respectively. The best age for the new normal event within the Kiaman is thus $263 \pm 5$ million years, which is distinguishable from the Oak Creek/Graham event. 